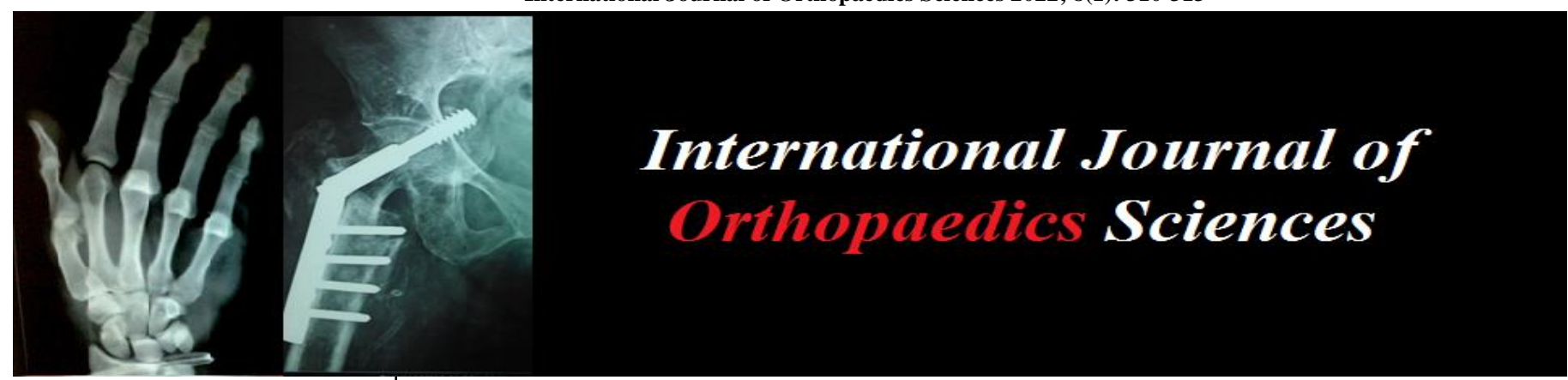

E-ISSN: 2395-1958

P-ISSN: 2706-6630

IJOS 2022; 8(1): 310-313

(C) 2022 IJOS

www.orthopaper.com

Received: 01-11-2021

Accepted: 03-12-2021

\section{Nikhil Sharma}

Peerless Hospital and BK Roy

Research Center Kolkata,

West Bengal, India

\section{Dr. Arun Gulati}

Department of Orthopaedics, Kalpana Chawla Government Medical College, Karnal,

Haryana, India
Corresponding Author: Nikhil Sharma

Peerless Hospital and BK Roy Research Center Kolkata,

West Bengal, India

\title{
Functional outcome of distal tibia fracture fixation with locking compression plate (LCP) using MIPO technique in a tertiary care hospital in eastern India
}

\section{Nikhil Sharma and Dr. Arun Gulati}

DOI: https://doi.org/10.22271/ortho.2022.v8.i1e.3032

\section{Abstract}

Background: The precarious blood supply and the scarcity of soft tissue envelope and the proximity to ankle joint makes the treatment of distal tibia fractures challenging. Over the years multiple modalities ranging from conservative measures to surgical interventions have been marred by an array of complications. Minimally Invasive Plate Osteosynthesis minimises soft tissue compromise while maintaining vascular integrity of the fractured fragments and the preserves the osteogenic haematoma. While using locking compression plate allows uncomplicated fracture healing and early return to function by providing a rigid biomechanical construct.

Methods: A total of 32 patients with distal tibial fractures treated by MIPO technique with LCP fixation were studied from August 2017 to May 2019 and were followed up at regular intervals for a period of 36 weeks.

Result: All fractures united within a range of 14-24 weeks and the mean time of radiological union/ weight bearing was 16.72 weeks. Superficial skin infection was observed in two patients $(5.5 \%)$ which settled down well with antibiotics and antiseptic dressing.

Conclusion: MIPO technique using LCP offers an attractive option for the management of closed fractures of the distal tibia while preserving the blood supply of soft tissue and bone as compared to the other treatment options. This study recommends its usage in such complex injuries.

Keywords: distal tibia fracture, MIPO, locking compression plates, minimally invasive plate osteosynthesis, closed fractures, ankle joint, ankle fractures

\section{Introduction}

Treatment of distal Tibia fractures has been a great challenge because of the precarious blood supply and paucity of soft tissue envelope in this part of the bone as well as its proximity to the ankle joint.

Simple fractures of distal tibia have been treated by various modalities, ranging from conservative methods to surgical intervention such as open reduction and internal fixation (ORIF) with the use of plates, external fixation and intra-medullary interlocking nailing (IMIN).

An array of complications has been encountered in the management of this fracture. Nonoperative treatment may be complicated by loss of reduction and subsequent malunion or nonunion. Open reduction and internal fixation using plates involves extensive soft tissue dissection with consequent periosteal injury and may be associated with wound ${ }^{[1-7]}$ Use of external fixators for distal Tibia fractures may result in insufficient reduction leading to malunion or non-union, pin tract infection, pin loosening and osteomyelitis ${ }^{[8-12]}$. The intramedullary interlocking nail spares the extraosseous blood supply, allows load sharing and avoids extensive soft tissue dissection. However, proximal and distal shaft fractures can be difficult to control with an intramedullary device, thereby increasing the frequency of malalignment. Concerns regarding difficulties in reduction, loss of reduction, inappropriate fixation in fractures with articular extension, anterior knee pain and hardware failure has procrastinated the acceptance of intramedullary nailing as a treatment of choice for fractures of the distal tibia ${ }^{[13-15]}$ Of late, Minimally Invasive Plate Osteosynthesis (MIPO) has found a place in the fixation of distal Tibia fractures after disappointing results were obtained 
following traditional methods of surgical stabilization of the same ${ }^{[16-25]}$

Minimally Invasive Plate Osteosynthesis (MIPO) offers biological advantages by minimizing soft tissue compromise and maintaining vascular integrity of the fracture fragments as well as preserving the osteogenic fracture-hematoma ${ }^{[26]}$.

The use of Locking Compression Plate (LCP) provides a rigid biomechanical construct allowing uncomplicated fracture healing and eventual early return to function.

In this study we aim to see the functional outcome of distal Tibia fracture fixation with Locking Compression Plates (LCP) using MIPO technique- a Prospective and observational study.

\section{Material and Methods}

A total of 36 patients with fractures of the distal tibia treated using Locking compression plate with MIPO technique were included in the study. This was a prospective study done at Peerless hospital and BK Roy Research Center, Kolkata from August 2017 to May 2019. In this prospective and observational study skeletally mature patients with closed extra-articular distal tibia fractures who presented within 7 days of injury and agreed upon providing informed written consent were included. Patients with open fractures, pathological fractures, intra-articular fractures, ipsilateral limb injuries and medical co-morbidities were excluded.

\section{Methodology}

After admission to the hospital a careful history was elicited from the patient or attendants to reveal the mechanism of injury and the severity of trauma. Patients were evaluated as per ATLS protocol. The patients were then assessed clinically to evaluate their general condition and the local injury. In general examination, the vital signs were recorded. Thorough local examination was done including the distal neurovascular status, deformity and soft tissue injury of the involved limb. Primary stabilization of the patient was done with above knee POP slab and elevation of the affected limb. All the necessary clinical details were recorded in proforma prepared for the study. Routine radiological and biochemical investigations were performed with X-ray of the affected limb with one joint above and below.

After due informed written consent the procedure was done under regional anaesthesia with tourniquet control with the patient in supine position on a radioluscent table. One dose of intravenous antibiotics was given at the time of induction of anaesthesia. Scrubbing, painting, and draping were done from above the knee down to the toes. Adequate closed reduction of the fracture was achieved by direct or indirect method using fluoroscopic guidance. A small vertical or curvilinear incision was made at the level of the medial malleolus. Subcutaneous tunneling was achieved with appropriate instrumentation. Plate held with Kocher's forceps or a plate holding device was tunneled across the fractured site to be seated over the bone. Preliminary fixation was achieved with $\mathrm{K}$ - wire or cortical screw followed by definitive fixation using locking screws proximal and distal to the fracture-site. A check for rotational malalignment was done. Wound was closed in layers. Tourniquet removed, compression dressing done and vascularity of limb was checked. In the post operative period the patient was given intravenous antibiotics for 2 days and then shifted to oral antibiotics which continued for 7 days after discharge.

In cases where there was an associated fibula fracture the fibula was fixed prior to fixation of tibia. The fibula was fixed where it was necessary to restore the stability and normal anatomy of the ankle joint or where it was considered helpful to have a template for length. Reduction was assessed repeatedly during the different steps of the operation using both visual (gross axial rotational alignment) and image intensifier control. An acceptable reduction was $<5^{\circ}$ of varus or valgus and $<10^{\circ}$ of anterior or posterior angulation and malrotation of less than $10^{\circ}$

Follow up was done at 2 weeks, 6 weeks, 10 weeks, 16 weeks, 22 weeks, 28weeks and 36 weeks interval with radiological evaluation and functional evaluation as per American Orthopaedic Foot and Ankle Society (AOFAS)AnkleHindfoot Score developed in 1994.

\section{Results}

Out of the total of 36 patients; 24 were male and 12 were female patients. The patients were in the age group of 25 to 67 years and the mean age being 47 years (Table-1). The mode of injury in 20 patients was found to be high energy trauma (RTA) while 16 patients sustained low energy trauma; accidental fall(Table 2). Fractures of the right side were more common with 19 patients while 17 had fractures of the left side. Out of 36 patients, 11 patients were seen to be having Grade zero soft tissue injury while 8 patients were having Grade I injury as per Tscherne - Gotzen Classification System (Table-3). The fractures of the distal tibia were classified according to the AO/OTA Classification(Table-4). All the patients were operated within a week of presentation to the hospital. Most of the patients were operated within 1 to 3 days of admission while 8 patients were operated within 24 hours (Table-5). The mean time of radiological union /weight bearing was 16.72 weeks with a range of 14-24 weeks (Table6). Superficial skin infection was observed in two patients $(5.5 \%)$ which settled down well with antibiotics and antiseptic dressing.

Table 1: Distribution of age of the patients

\begin{tabular}{|c|c|c|}
\hline Age Group (in years) & Number & $\%$ \\
\hline $25-39$ & 9 & $25.0 \%$ \\
\hline $40-54$ & 19 & $52.8 \%$ \\
\hline $55-69$ & 8 & $22.2 \%$ \\
\hline Total & 36 & $100.0 \%$ \\
\hline
\end{tabular}

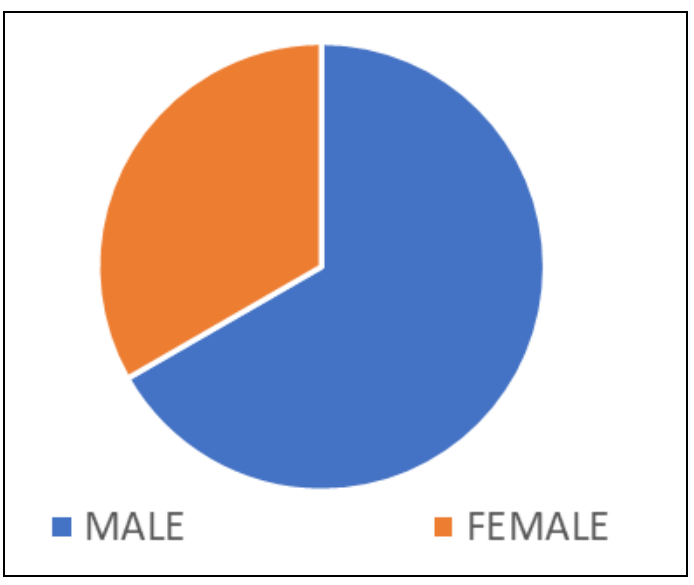

Fig 1: Gender distribution

Table 2: Distribution of mode of injury of the patients

\begin{tabular}{|c|c|c|}
\hline Mode of injury & Number & \% \\
\hline Fall & 16 & $44.4 \%$ \\
\hline RTA & 20 & $55.6 \%$ \\
\hline Total & 36 & $100.0 \%$ \\
\hline
\end{tabular}




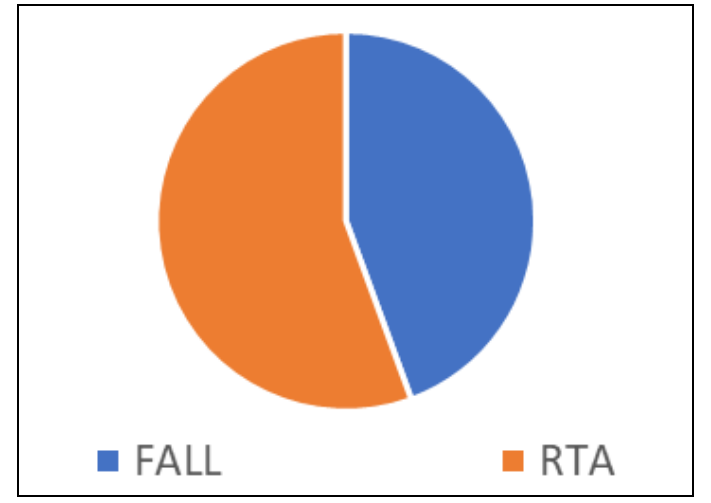

Fig 2: Side dominence

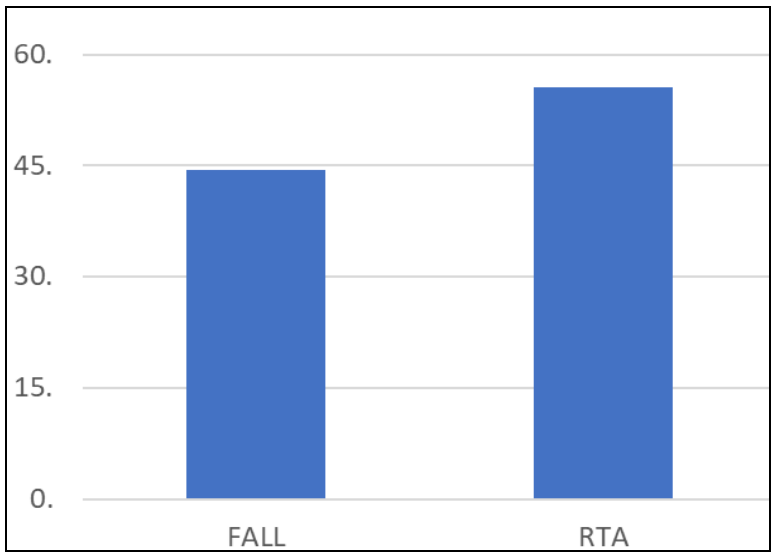

Fig 3: Mechanism of Injury

Table 3: Distribution of TG classification of the patients

\begin{tabular}{|c|c|c|}
\hline TG classification & Number & \% \\
\hline O & 12 & $33.3 \%$ \\
\hline I & 8 & $22.2 \%$ \\
\hline Nil & 16 & $44.4 \%$ \\
\hline Total & 36 & $100.0 \%$ \\
\hline
\end{tabular}

Table 4: Distribution of AO classification of the patients

\begin{tabular}{|c|c|c|}
\hline AO classification & Number & \% \\
\hline A 1 & 14 & $38.9 \%$ \\
\hline A2 & 17 & $47.2 \%$ \\
\hline A 3 & 5 & $13.9 \%$ \\
\hline Total & 36 & $100.0 \%$ \\
\hline
\end{tabular}

Table 5: Time interval between injury and surgery (days)

\begin{tabular}{|c|c|}
\hline $\begin{array}{c}\text { Descriptive } \\
\text { Statistics }\end{array}$ & $\begin{array}{c}\text { Time interval between injury and } \\
\text { surgery (days) }\end{array}$ \\
\hline Mean & 2.75 \\
\hline Range & $1-6$ \\
\hline
\end{tabular}

Table 6: Time of radiological union and weight bearing (in weeks)

\begin{tabular}{|c|c|}
\hline Descriptive tatistics & $\begin{array}{c}\text { Time of radiological union and } \\
\text { weight bearing (in weeks) }\end{array}$ \\
\hline Mean & 16.72 \\
\hline Range & $14-24$ \\
\hline
\end{tabular}

Table 7: Distribution of final interpretation and result of the patients as per AOFAS score.

\begin{tabular}{|c|c|c|}
\hline Final interpretation and result & Number & \% \\
\hline Excellent & 14 & $38.9 \%$ \\
\hline Fair & 5 & $13.9 \%$ \\
\hline Good & 15 & $41.7 \%$ \\
\hline Poor & 2 & $5.6 \%$ \\
\hline Total & 36 & $100.0 \%$ \\
\hline
\end{tabular}

None of the cases showed malalignment. Non-union/implant infection was not seen in any of the patients taken for study.

Final results of the study were based on AOFAS score. Excellent results were seen in 14 patients; good results in 15 patients; 5 had a fair outcome and 2 patients had poor results. The average AOFAS score was 86(Table-7).

\section{Discussion}

Historically obtaining alignment and maintaining stability in the treatment of distal tibia fractures has been a challenging task for the orthopedic traumatologist. Though the conservative management of these fractures has been described [27, 28] these methods have been replaced by operative techniques for displaced or irreducible fractures.

MIPO is now an established technique for management of fractures of the distal tibia. A number of comprehensive reviews of the technique have been made.

Malalignment has been recognized as a potential pitfall when using indirect reduction techniques and vigilance towards intra operative realignment has been stressed as a key for preventing alignment problems. In this study alignment was restored and maintained using MIPO technique in all the cases. Only two cases of malalignment were observed but the malalignment was within the acceptable limit and therefore had no bearing on ultimate functional outcome.

In the study by Collinge and Protzman ${ }^{[29]}$ of the total 38 fractures, they had 1 malalignment with $>5^{\circ}$ angulation and 1 cm shortening. Redfern et al. ${ }^{[30]}$. had 1 case of malunion in a series of 20 patients treated with MIPO with DCP. Helfet et $a l$, in their series of 20 patients of distal tibial fractures treated with MIPO reported 4 cases of malunion; 2 with $>5^{\circ}$ of varus and 2 with $>10^{\circ}$ of recurvatum.

In our study superficial skin infection was seen in two patients $(5.5 \%)$. Infection rates have also generally been reported as being low, with Krackhardt et al. ${ }^{[31]}$ reporting three (4\%) cases of infection, all occurring in patients with closed fractures but extensive soft tissue injury. Similarly low infection rates $(<8 \%)$ with MIPO have been found by other authors ${ }^{[32-36]}$. Higher infection rates have been reported. Lau et al. ${ }^{[37]}$ reported a $15 \%$ rate of late infection in a series of 48 patients and Hazarika et al ${ }^{[38]}$, found three (15\%) wound infections in their series of twenty patients.

In the present study clinical results were evaluated according to AOFAS Score and the average AOFAS Score was 86. Collinge and Protzman reported good to excellent results with a mean AOFAS Score of 85. In the study under taken by Redfern et al, ${ }^{[30]}$ patients returned to their pre-injury level of activity.

The mean AOFAS Score in the MIPO group of the study by JJ Guo et al. ${ }^{[39]}$ was 83.9. Comparable results have been observed in this study also.

\section{Conclusion}

MIPO technique using LCP offers an attractive option for the management of closed fractures of the distal tibia. In addition to providing excellent fracture stability while preserving the vascularity to the bone and soft tissue, MIPO technique avoids the complications associated with other forms of fixation available for these fractures.

\section{References}

1. Fisher WD, Hambledon DL. Problems and pitfalls of compression fixation of long bone fractures: A review of results and complications. Injury. 1978;10:99-107.

2. McFerran MA, Smith SW, Boulas HJ, Schwartz HS. 
Complications encountered in the treatment of pilon fractures. J Orthop Trauma. 1992;6:273-85.

3. Olerud S, Karlstrom G. Tibial fractures treated by AO compression osteosynthesis. Acta Orthop Scand Suppl. 1972;1:1-104.

4. Ruedi T, Allgower M. Fractures of the lower end of the tibia into the ankle joint. Injury. 1969;1:92.

5. Ruedi T, Allgower M. The operative treatment of intraarticular fractures of the lower end of the tibia. Clin Orthop. 1979;138:105-10.

6. Kellam JF, Waddell JP. Fractures of the distal tibial metaphysis with intraarticular extension: the distal tibial explosion fracture. J Trauma. 1979, 19.

7. Perren SM. Evolution of the internal fixation of long bone fractures. Bone \& Joint Journal. 2002;84(8):1093110.

8. Pugh KJ, Wolinsky PR, McAndrew MP, et al. Tibial pilon fractures: a comparison of treatment methods. J Trauma. 1999;47:937-941.

9. Bone L, Stegemann PM, McNamara K, et al. External fixation of severely comminuted and open tibial pilon fractures. Clin Orthop Relat Res. 1993;292:101-107.

10. Court-Brown CM, Walker C, Garg A, et al. Half-ring external fixation in the management of tibial plafond fractures. J Orthop Trauma. 1999;13:200-206.

11. Marsh JL, Bonar S, Nepola JV, et al. Use of an articulated external fixator for fractures of the tibial plafond. J Bone Joint Surg Am. 1995;77:1498-1509.

12. Marsh JL, Weigel D, Dirschl D. Tibial plafond fractures. How do these function over time? J Bone Joint Surg Am. 2003;85:287-295.

13. Nork SE, Schwartz AK, Agel J, et al. Intramedullary nailing of distal metaphyseal tibial fractures. J Bone Joint Surg Am. 2005;87:1213-1221.

14. Mosheiff R, Safran O, Segal D, et al. The unreamed tibial nail in the treatment of distal metaphyseal fractures. Injury. 1999;30:83-90.

15. Robinson CM, McLauchlan GJ, McLean IP, et al. Distal metaphyseal fractures of the tibia with minimal involvement of the ankle. J Bone Joint Surg Br. 1995;77:781-787.

16. Schmidt AH, Finkemeier CG, Tornetta III P. Treatment of closed tibial fractures. JBJS. 2003;85(2):352-68.

17. Tong GO, Bavonratanavech S. AO Manual of Fracture Management Minimally Invasive Plate Osteosynthesis. Thieme. 2007, 305-325.

18. Collinge C, Kuper M, Larson K, Protzman R. Minimally invasive plating of high-energy metaphyseal distal tibia fractures. Journal of orthopaedic trauma. 2007;21(6):35561

19. Collinge C, Sanders R, DiPasquale T. Treatment of complex tibial periarticular fractures using percutaneous techniques. Clin Orthop RelatRes. 2000;375:69-77.

20. Helfet DL, Shonnard PY, Levine D et al. Minimally invasive plate osteosynthesis of distal fractures of the tibia. Injury. 1997;28(Suppl 1): S- A42-S-A48

21. Khoury A, Liebergall M, London E et al. MIPO of distal tibial fractures. Foot Ankle Int. 2002;23:818-824.

22. Maffulli N, Toms AD, Mc Murtie A, et al. MIPO of distal tibial fractures. Int Orthop. 2004;28:159-162.

23. Oh CW, Kyung HS, Park IH, et al. Distal tibia metaphyseal fractures treated by percutaneous plate osteosynthesis. Clin Orthop Relat Res. 2003;408:286291.

24. Toms AD, McMurtie A, Maffulli N. MIPO of the distal tibia. J Foot Ankle Surg. 2004;43:199-203.

25. Burkalter WE, Protzman R. The tibial shaft fracture. J Trauma. 1975;15:785-781.

26. Farouk O, Krettek C, Miclau T, Schandelmaier P, Guy P, Tscherne H. Minimally invasive plate osteosynthesis and vascularity: preliminary results of a cadaver injection study. Injury. 1997;28:A7-12.

27. Digby JM, Holloway GMN, Webb JK. A study of function after tibial cast bracing. Injury. 1983;14:432e439.

28. Sarmiento A, Latta LL. 450 closed fractures of the distal third of the tibia treated with a functional brace. Clin Orthop Relat Res. 2004;428:261e271.

29. Collinge C, Protzman R. Outcomes of minimally invasive plate osteosynthesis for metaphyseal distal tibia fractures. J Orthop Trauma. 2010;24(1):24-9.

30. Redfern DJ, Syed SU, Davies SJ. Fractures of the distal tibia: minimally invasive plate osteosynthesis. Injury. 2004;35(6):615-20

31. Krackhardt T, Dilger J, Flesch I, Höntzsch D, Eingartner C, Weise K. Fractures of the distal tibia treated with closed reduction and minimally invasive plating. Archives of orthopaedic and trauma surgery. 2005;125(2):87-94.

32. Bahari S, Lenehan B, Khan H, McElwain JP. Minimally invasive percutaneous plate fixation of distal tibia fractures. Acta Orthop Belg. 2007;73(5):635-40.

33. Khoury A, Liebergall M, London E, Mosheiff R. Percutaneous plating of distal tibial fractures. Foot Ankle Int 2002;23:818-24.

34. Maffulli N, Toms AD, McMurtie A, Oliva F. Percutaneous plating of distal tibial fractures. Int Orthop 2004;28:159-62.

35. Oh CW, Kyung HS, Park IH, et al. Distal tibia metaphyseal fractures treated by percutaneous plate osteosynthesis. Clin Orthop Relat Res 2003;408:286-91.

36. Pai V, Coulter G, Pai V. Minimally invasive plate fixation of the tibia. Int Orthop. 2007;31(4):491-6.

37. Lau TW, Leung F, Chan CF, Chow SP. Wound complication of minimally invasive plate osteosynthesis in distal tibia fractures. International orthopaedics. 2008;32(5):697

38. Hazarika S, Chakravarthy J, Cooper J. Minimally invasive locking plate osteosynthesis for fractures of the distal tibia--results in 20 patients. Injury. 2006;37(9):87787.

39. Guo JJ, Tang N, Yang HL, Tang TS. A prospective, randomised trial comparing closed intramedullary nailing with percutaneous plating in the treatment of distal metaphyseal fractures of the tibia. J Bone Joint Surg Br. 2010;92(7):984-8. 